Aeration processes for the biological oxidation of waste waters were described by Mr. A. L. Downing. In effect, the activated sludge process is a very dilute fermentation. The whole process must be carried out as cheaply as possible. Various devices used for aerating the waste liquors were described, such as the induction of air through a Venturi tube and the use of a submerged impeller and sparger. The effeets of bubble diameter and depth of liquid through which the bubbles travel were also studied in tap water containing 5 p.p.m. anionic surface-active agent. The effects of surface-active agents on mass transfer were found to depend on the method of aeration. As would be expected, the rate of absorption was roughly inversely proportional to the bubble diameter, and the oxygen absorbed per unit consumption of energy tended to decrease with increased depth of liquid.

The shortness of the Symposium imposed very strict scheduling and handicapped free interchange of opinions. The discussion was held back until several principal papers had been given, and this led to some 'cooling off', which was also encouraged by the separation of question and response. There was a tendeney for many of the contributions to be too restricted in scope and lacking in general philosophical content. Perhaps this is a way of saying that they were too specialized for one-half of the audience. Again, a contribution on equipment design, or even some account of the problems associated with it, even to such special details as design of valves, sampling devices, probes and electrodes, might have brought a little more practicality and scope for argument.

The meeting, although demonstrating clearly that biologists and chemical engineers speak rather different languages even when working on the same processes, did indicate that the barriers are not impassable. Moreover, who knows, in crossing the perilous mountains between the two disciplines, one might come across that 'abominable noman', the biochemical engineer. The proceedings of the symposium are to be published in Transactions of the Institution of Chemical Engineers. D. J. D. HockeNHULL

\title{
COSMIC RAY RESEARCH IN LATIN AMERICA
}

$\mathrm{T}$ HE third Latin-American conference and course on cosmic ray physics was held in Mexico during June 26-July 5. It was arranged by Profs. M. S. Vallarta and J. Roederer on behalf of the Latin-American Council for Cosmic Ray Research under the auspices of Unesco, the Mexican Nuclear Energy Commission, and the U.S. Space Science Board.

The meetings were held at the University of Mexico, famous for the elegance of its remarkable architecture, and at the headquarters of the Nuclear Energy Commission. There were present some 25-30 representatives from Argentina, Bolivia, Brazil, Chile, Mexico, Peru, the United States and the United Kingdom. The course consisted partly of original contributions and partly of lectures of a review nature. The topics covered in the lectures included the nature and origin of the galactic cosmic rays and solar-produced high-energy particles, the intensity variations of the galactic radiation and their relation to solar activity and the structure of the interplanetary magnetic field, the motion of primary cosmic rays in the geomagnetic field, the properties and origin of the Earth's radiation belts, and solar radio astronomy.

The Latin-American countries between them operate a chain of neutron monitors covering a wide belt of latitude from Mexico in the north to Ellsworth in Antarctica, and a good deal of the original work reported at the meeting was concerned with the analysis and interpretation of the data from these stations.

In particular, the remarkable cosmic ray intensity variations during July 1959 and November 1960 (when there were examples both of decreases in the intensity of galactic particles and of injection of additional low-energy particles by the Sun) have been very carefully analysed by the Argentinian, Bolivian and Brazilian groups. In discussing the events of November 1960 the Argentinian workers arrive at the conclusion that the main intensity increase starting at 1930 U.T. on November 12 was due to the envelopment of Earth by a cloud of magnetized solar plasma contrining trapped solar particles generated by the $3+$ flare which began at about 1330 O.T. on that day. They also conclude that the presence of the magnetic field associated with the plasma was responsible for producing the decrease in intensity of the galactic cosmic rays observed at this time. They attribute the increase in intensity of solar particles between 1330 and 1930 U.T., prior to the main increase, to leakage from the trapping field. in the plasma.

The Bolivian group, which operates the extremely well-appointed laboratory at Chacaltaya (altitude 5,200 metres above sea-level) includes in its cosmic ray activities the study of both large air showers and intensity variations related to solar processes. In* cluded in the work reported by this group was an account of the rapid, short-lived intensity decrease observed on November 13, 1960, by means of its neutron monitor, which has the very high counting rate of $\sim 5 \times 10^{5}$ per $\mathrm{hr}$. Immediately after the magnetic storm sudden commencement at $10 \mathrm{hr}$. 21 min. U.T, on that day, the cosmic-ray intensity started to decrease and shortly after $1300 \mathrm{hr}$. U.T. it dropped suddenly, remaining 3 or 4 per cent below the general prevailing level for about $1 \frac{1}{4} \mathrm{hr}$., after which it returned suddenly to the pre-drop value Analysis of data from other stations showed that this phenomenon happened on a world-wide scale, and the Bolivian group concludes that this kind of modulation of the galactic cosmic-ray intensity could only be produced if the solar plasma contained a very welldefined region of relatively high magnetic field strength.

The work of the cosmic ray group in Santiago at the University of Chile, reported by Prof. G. Alvial, is principally concerned with the investigation of the primary cosmic rays using nuclear emulsion techniques, and he described work which has been carried out on charge determination of heavy nuclei in a stack of $G-5$ emulsion exposed at $131,000 \mathrm{ft}$. over Minnesota. Charge determination by two methods 
gives agreement to better than one unit. One particle has been found with $Z=30$.

Mrs. R. Gall, of the Institute of Geophysics, University of Mexico, gave an account of the work carried out there by the theoretical group on the trapping of charged particles in the geomagnetic field and on the relation between the radiation belts and the inner allowed region of Störmer. Work is also being carried out on the motion of cosmic ray albedo particles in Earth's field and on the changes in threshold momenta resulting from the secular variation in the geomagnetic field. At some points on Earth's surface these changes have amounted to as much as 25 per cent during the past hundred years.

This course, which is a biennial event, provides, in addition to the presentation of original work and review lectures, a forum for the discussion and co-ordination of future programmes in cosmic-ray research in the participant countries. The two previous courses were held in La Paz, Bolivia, and San Carlos de Bariloche, Argentina, and it is intended that the next one should be held once again in Bolivia. In a report of this length it has only been possible to select a few representative aspects of the work reported by the Latin-American groups.

H. ELLIOT

\section{PHARMACEUTICAL CONTROL IN BRITAIN}

$I^{\mathrm{N}}$ $\mathrm{N}$ his chairman's address to the British Pharmaceutical Conference, held at Portsmouth during September 18-22, Dr. D. C. Garratt states a case for a more effective control of the quality of medicinal substanees. Drugs not governed by official standards should not become available to the public except under a notification scheme, similar to that already in force for pesticides, so that their clinical characters and standards of purity, with appropriate methods of analysis, would have prior approval. Standards for all medicines should be enforeed by testing in regional laboratories specialized for the purpose and maintained by the Ministry of Health. For reputable approved firms, the contractor's own inspection organization could be given the initial responsibility for compliance of goods with specification. The pharmaceutical analysis involved should be admitted as a distinct discipline, by the institution of special training courses and recognized qualifications.

At present, control analysis is too often rendered pointless by insufficient attention to the precision of the methods involved; and for a full realization of the potentialities of such techniques as, for example, ultra-violet spectrophotometry, a national collection of standard specimens of authentic materials of known impurity content is essential. Authority for the enforcement of those standards should be incorporated in an Act of Parliament.

It should be every analyst's concern to consider what can be done to reduce costs of examinations, for example, by using equally effective, but cheaper, solvents, by applying rapid instrumental techniques or, where possible, by replacing costly bio-assay investigations by simpler paper chromatographic techniques.

Dr. Garrett suggests that the public would receive better protection if the control of drugs were divorced from the present Food and Drugs Act and incorporated in a new Medical Substances and Preparations Act built around Sections 11, 12 and 13 of the Pharmacy and Medicines Act. Imported drugs should be subject to stringent examination by analysts of acceptable status. Such status might be conditional on the possession of a special diploma incorporated as a requirement of competence in the proposed Medical Substances and Preparations Act. Examinations for such diploma qualifications would be conducted by those chemical or pharmaceutical institutions approved by the Ministry of Health.

\section{THE LABORATORY OF THE GOVERNMENT CHEMIST}

T HE very varied work done in the Laboratory of the Government Chemist during 1960 has recently been reported*. The Laboratory, which forms part of the Department of Scientific and Industrial Research, exists to provide a service to any Government department that requests it on matters broadly concerned with chemistry, and more particularly with chemical analysis. The Laboratory is the oldest Government chemical institution in the Commonwealth. It was created in 1842 by the Board of Inland Revenue, principally to assist the revenue authorities in detecting and preventing the adulteration of tobacco with worthless additives. The special responsibilities which the Laboratory retains to H.M. Customs and Excise are highlighted by the number of samples received from this authority. Of a total of 327,460 samples examined and reported on by the Laboratory during the year, no less than 280,125 were submitted by H.M. Customs and Excise. These samples cover a wide range of dutiable com-

* Department of Scientiffe and Industrial Research: Laboratory of the Government Chemist. Report of the Government Chemist, 1960 Pp. iv + 79. (London: H.M.S.O., 1961.) 5s. net, modities such as wines, beers and spirits, sugar, textiles, fuel oils, etc.

The statutory duties of the Government Chemist under the Food and Drugs Act, the Fertiliser and Feeding Stuffs Act, and the National Health Act, involve the Laboratory in such work as the analysis of orange juice, dried milk, fertilizers, pesticide chemicals and formulations thereof, pharmaceuticals and drugs, canned foods. Examples of the variety of this work are the determination of glycogen in oysters and the iodine content of school dinners.

An organization which exists to provide an advisory service must carry out a considerable number of routine analyses as, for example, on the variety of materials purchased by various Government departments ; this work varies little from year to year.

Important work from the public health point of view concerns the examination of water and sewage. Much attention is given to the control of fluoridation in municipal supplies (where this is practised). The control of micro-organisms in the Serpentine bathing area is an item of special interest to Londoners. 